\title{
Letters
}

\section{Hepatocyte nuclear factor-1 $\beta$ (MODY5) gene mutations in Scandinavian families with early-onset diabetes or kidney disease or both}

Dear Sir,

We have recently identified mutations in the hepatocyte nuclear factor $(H N F)-4 \alpha$ [maturity-onset diabetes of the young (MODY)] 1, glucokinase (MODY2) HNF-1 $\alpha$ (MODY3), and mitochondrial $t R N A^{\text {Leu(UUR) }}$ genes in 15 out of $115(13 \%)$ Scandinavian patients with familial early-onset ( $\leq 40$ years) diabetes [1]. The homeodomain-containing transcription factor HNF- $1 \beta$ is mainly expressed in the kidney, liver, intestine, lungs, and pancreas and interacts with HNF-1 $\alpha$ at the protein level by forming heterodimers $[2,3]$. Therefore it represents a logical candidate gene for early-onset diabetes. Mutations in the $H N F-1 \beta$ gene have recently been described in two Japanese MODY5 families with early-onset diabetes and kidney disease $[4,5]$. The aim of the present study was to examine whether mutations in the $H N F-1 \beta$ gene contribute to familial early-onset diabetes or kidney disease or both in Scandinavia. We chose 115 unrelated patients with early-onset diabetes for mutation screening of the $H N F-1 \beta$ gene [1]. In addition, 15 patients diagnosed with diabetic nephropathy were also included in the mutation screening [age at onset of diabetes $38 \pm 3$ years, duration of diabetes $20 \pm 2$ years, BMI $29.5 \pm 1.8 \mathrm{~kg} / \mathrm{m}^{2}$, and albumin excretion rate (AER) $601 \pm 221 \mu \mathrm{g} / \mathrm{min}]$. Diagnosis of kidney disease was based upon AER exceeding $200 \mu \mathrm{g} / \mathrm{min}$ on at least two occasions or serum creatinine concentrations higher than $150 \mu \mathrm{mol} / \mathrm{l}$ or both. Of the patients four had end-stage kidney disease, four had increased serum creatinine concentrations and seven had either microalbumiuria or proteinuria. The allele frequencies of detected sequence variants were also tested in 92 non-diabetic control subjects without a family history of diabetes.

The minimal promoter region and 9 exons of the $H N F-1 \beta$ gene were screened with the single strand conformation polymorphism (SSCP) technique using an ABI377 DNA sequencer (Applied Biosystems, Foster City, Calif., USA). We identified five novel variants: two amino acid substitutions (A241T in exon 3 and G492S in exon 7), two intronic nucleotide substitu-

Corresponding author: M. Lehto, Department of Endocrinology, Wallenberg Laboratory (Entrance 46), MAS, S-20502 Malmö, Sweden tions (IVS6 $+26 \mathrm{~T} \rightarrow \mathrm{C}$, IVS8-66C $\rightarrow \mathrm{T}$ ) and one nucleotide substitution $(\mathrm{C} \rightarrow \mathrm{G}) 31$ bp upstream from the start codon. In addition, two previously reported intronic variants, IVS $8+48$ insC and IVS8-22C $\rightarrow \mathrm{T}$ were also identified $[4,6]$. The allele frequencies of these variants did not differ between diabetic patients and non-diabetic control subjects (Table 1).

The two novel intronic variants (IVS6 $+26 \mathrm{~T} \rightarrow \mathrm{C}$, IVS8-66C $\rightarrow T$ ) and one nucleotide substitution $(C \rightarrow G)$ located in the 5 '-untranslated region were considered as polymorphisms rather than mutations as they did not cosegregate with familial diabetes or kidney disease. The missense mutation A241T was identified in one out of 15 patients with diabetic nephropathy (age at onset of diabetes 25 years, duration of diabetes 29 years). This patient had undergone kidney transplantation at age 40 years. Because there had been no kidney biopsy before kidney transplantation, it was not possible to decide whether the patient had diabetic nephropathy or not, but renal cysts had been excluded by ultrasound. The A241T variant was not found in 3 diabetic relatives or in 92 non-diabetic control subjects. The variant is located in the homeodomain region of the $H N F-1 \beta$ gene, which is essential for DNA-binding. This highly homologous region in both $H N F-1 \beta$ and $H N F-1 \alpha$ genes is also conserved between human, rat and mouse sequences.

The G492S variant was detected in four diabetic probands with early-onset diabetes and in three non-diabetic control subjects. In total 39 family members of the 4 diabetic probands were tested for this variant. There were more diabetic patients among the mutation carriers than among the non-carriers (10/ 13 carriers vs 9/26 non-carriers; Fisher's Exact test $p<0.05)$ despite similar age $(54 \pm 3.6$ vs $52 \pm 4.3$ years $)$ and BMI $(27 \pm 1.0$ vs $\left.26 \pm 0.9 \mathrm{~kg} / \mathrm{m}^{2}\right)$. Also ten diabetic carriers of the G492S mutation had an earlier age at onset than nine diabetic family members without the mutation $(31 \pm 15$ vs $57 \pm 15$ years, the Mann-Whitney test, $p=0.003)$. No significant differences were observed in $\mathrm{HbA}_{1 \mathrm{C}}(7.6 \pm 0.6$ vs $6.4 \pm 0.5 \%)$, fasting blood glucose $(9.1 \pm 1.3 \mathrm{vs} 7.1 \pm 0.9 \mathrm{mmol} / \mathrm{l})$ and 30 -min insulin concentration during OGTT $(37.8 \pm 8.2$ vs $44.8 \pm 13 \mathrm{mU} / \mathrm{l})$ or AER ( $82 \pm 67$ vs $17 \pm 10 \mu \mathrm{g} / \mathrm{min})$ between carriers and noncarriers. The glycine at codon 492 is located in the carboxy-terminal region of the HNF- $1 \beta$, which is conserved between human, rat and mouse sequences. Although we did not find any difference in allele frequency of the G492S variant between diabetic and control subjects, this variant could still contribute to diabetes by accelerating the development of diabetes.

To date only two mutations in the $H N F-1 \beta$ gene, R177X and A263fsinsCC, have been associated with both early-onset diabetes and renal dysfunction $[4,5]$. These mutations resulted in a considerable reduction of transactivation of the GLUT2 
Table 1. The $H N F-1 \beta$ gene sequence variants detected in 130 diabetic patients with early-onset diabetes or diabetic nephropathy or both

\begin{tabular}{|c|c|c|c|c|c|c|}
\hline \multirow[t]{2}{*}{ Location } & \multirow{2}{*}{$\begin{array}{l}\text { Sequence } \\
\text { variation }\end{array}$} & \multirow{2}{*}{$\begin{array}{l}\text { Nucleotide } \\
\text { position }\end{array}$} & \multirow[t]{2}{*}{ Designation } & \multirow{2}{*}{$\begin{array}{l}\text { Restriction } \\
\text { enzyme }^{\mathrm{c}}\end{array}$} & \multicolumn{2}{|c|}{ Allele frequency } \\
\hline & & & & & $\begin{array}{l}\text { Diabetic } \\
\text { patients } \\
(n=130)\end{array}$ & $\begin{array}{l}\text { Non-diabetic } \\
\text { control subjects } \\
(n=92)\end{array}$ \\
\hline exon $3^{a}$ & $\mathrm{GCG} \rightarrow \mathrm{ACG}$ & 177 & $\mathrm{~A} 241 \mathrm{~T}$ & BstU I (+) & $259 / 1$ & $184 / 0$ \\
\hline Intron $6^{\mathrm{a}}$ & $\mathrm{T} \rightarrow \mathrm{C}$ & +26 & IVS6+26T $\rightarrow$ C & BseD I (-) & $237 / 23$ & $167 / 17$ \\
\hline $\operatorname{exon} 7^{a}$ & $\mathrm{GGC} \rightarrow \mathrm{AGC}$ & 135 & G492S & BseD I (+) & $256 / 4$ & $181 / 3$ \\
\hline Intron 8 & $\mathrm{C} \rightarrow \mathrm{T}$ & -22 & IVS8-22C $\rightarrow$ T & - & ND & ND \\
\hline
\end{tabular}

${ }^{\mathrm{a}}$ Novel variants; ${ }^{\mathrm{b}} 5$ '-untranslated region; ${ }^{\mathrm{c}}$ The plus and minus signs indicate gain and loss of restriction site, respectively; ${ }^{\mathrm{d}}$ upstream from start codon; ND: Not determined

gene in liver cell and pancreatic beta-cell lines [7]. In keeping with our findings in the patients with early-onset diabetes, mutations in the $H N F-1 \beta$ gene seem to be uncommon in French and British families with MODY diabetes [6, 8]. Two novel missense mutations, A241T and G492S, might, however, be associated with kidney disease and earlier onset of diabetes. Due to incomplete segregation, the final explanation of their pathogenic role in diabetes and kidney disease requires functional studies.

Yours sincerely,

J.P. Weng, M Lehto, C. Forsblom, X. Huang,

H. Li, L. C. Groop

\section{References}

1. Lehto M, Wipemo C, Ivarsson S-A et al. (1999) High frequency of mutations in MODY and mitochondrial genes in Scandinavian patients with familial early-onset diabetes. Diabetologia 42: 1131-1137

2. Rey-Campos J, Chouard T, Yaniv M, Cereghini S (1991) vHNF1 is a homeoprotein that activates transcription and forms heterodimers with HNF-1. EMBO J 10: 1445-1457
3. De Simone V, De Magistris L, Lazzaro D et al. (1991) LFB3, a heterodimer-forming homeoprotein of the LFB1 family, is expressed in specialized epithelia. EMBO J 10: 1435-1443

4. Horikawa Y, Iwasaki N, Hara M et al. (1997) Mutation in hepatocyte nuclear factor- $1 \beta$ gene (TCF2) associated with MODY. Nat Genet 17: 384-385

5. Nishigori H, Yamada S, Kohama Tet al. (1998) Frameshift mutation, A263fsinsGG, in the hepatocyte nuclear factor$1 \beta$ gene associated with diabetes and renal dysfunction. Diabetes 47: 1354-1355

6. Beards F, Frayling T, Bulman M et al. (1998) Mutations in hepatocyte nuclear factor $1 \beta$ are not a common cause of maturity-onset diabetes of the young in the U.K. Diabetes 47: 1152-1154

7. Tomura H, Nishigori $H$, Sho K, Yamagata K, Inoue I, Takeda J (1999) Loss-of-function and dominant-negative mechanisms associated with hepatocyte nuclear factor1beta mutations in familial-Type II diabetes mellitus. J Biol Chem 274: 12975-12978

8. Chevre JC, Hani EH, Boutin P et al. (1998) Mutation screening in 18 Caucasian families suggest the existence of other MODY genes. Diabetologia 41: 1017-1023

\section{Accuracy of fasting glucose to diagnose diabetes in Brazilian subjects}

\begin{abstract}
Dear Sir,
In a recently published article, the DECODE Study Group looked at the accuracy of fasting plasma glucose to define diabetes in a sample of more than 45000 people from $20 \mathrm{Eu}$ ropean epidemiological studies [1]. They observed that among people with a diabetic 2-hour plasma glucose of $11.1 \mathrm{mmol}$ or more during an oral glucose tolerance test (OGTT) more than $50 \%$ had a fasting plasma glucose (FPG) less than $7.0 \mathrm{mmol} / \mathrm{l}$ (the revised FPG criteria of diabetes [2, 3]) and in
\end{abstract}

Corresponding author: Dr. G. Velho, INSERM U-342, Hôpital Saint-Vincent-de-Paul, 82 Avenue Denfert Rochereau, 75014 Paris, France
$31 \%$ it was less than $6.1 \mathrm{mmol} / 1$ (the revised criteria of normal FPG). These data contrast with data from the United States and the Pacific Islands where a fasting blood glucose of $7.0 \mathrm{mmol} / \mathrm{l}$ was roughly equivalent, as a diagnostic cutpoint, to a 2-h plasma glucose of $11.1 \mathrm{mmol} / \mathrm{l}[2,3]$. These contrasting results fuel the controversy on whether or not the OGTT should be kept as a diagnostic tool of diabetes [2-4], and the DECODE Study Group report concludes that it is important to further analyse the impact of using only fasting plasma glucose for diagnosing diabetes in other populations [1].

We have analysed a sample of 6066 subjects without previously known diabetes who underwent a 75-g OGTT for diagnostic purposes at the H.Pardini Istitute of Clinical Pathology in the city of Belo Horizonte, state of Minas Geraes, Brazil. The subjects were referred by their doctors for the OGTT, either because they had a family history of Type II (non-insulindependent) diabetes mellitus, because of a clinical suspicion of diabetes, or as part of a health check-up. Women known to be pregnant were not included in the study. The average age 